\title{
A Comparison of Adrenalin and Glucagon Effects on Carbohydrate Levels of Larval and Adult Rana pipiens ${ }^{1}$
}

\author{
Eugenia S. Farrar and B. E. Frye \\ Department of Zoology, low'a State University, Ames, Low'a 5001l, and Office of the Dean, 2522 \\ Literature, Science and the Arts Building. University of Michigan. Ann Arbor, Michigan 48104
}

Accepted July 10, 1979

\begin{abstract}
Hyperglycemia was observed in frogs after single ip injections of doses above $50 \mu \mathrm{g} / \mathrm{kg}$ of adrenalin and glucagon. Blood glucose responses were maximal at $3 \mathrm{hr}$ and lasted at least 5 hr. Lactacidemia was apparent after treatment with adrenalin at doses of $50 \mu \mathrm{g} / \mathrm{kg}$ and above. The increase in lactate was apparent by $1 \mathrm{hr}$ and had dropped to control levels by 5 hr. Tissue glycogen loss was not observed after treatment with either hormone in adults. Preliminary studies with tadpoles indicated a hyperglycemic response to adrenalin and glucagon at doses of $1.0 \mathrm{mg} / \mathrm{kg}$ and an increase in lactate after injection of a $1.0 \mathrm{mg} / \mathrm{kg}$ dose of adrenalin. Liver glycogen loss was observed following glucagon but not adrenalin. Both hormones stimulated glucose release from liver slices of frogs and tadpoles.
\end{abstract}

Normal resting levels of blood glucose are lower in amphibians than in any other vertebrates when measurements are made under comparable conditions, including temperatures (Umminger, 1977). Metabolism is presumably not dependent upon closely regulated blood glucose levels (Copeland and deRoos, 1971) and metabolic rate may be independent of blood glucose levels in amphibians (Umminger, 1977). However, some regulation of blood glucose does occur and most hormones involved in regulation of mammalian carbohydrate metabolism have been shown to be active in amphibians including the hyperglycemic-glycogenolytic hormones, adrenalin and glucagon (Leibson and Plisetskaya, 1973). In mammals glucagon is involved in acute regulation of blood glucose levels while adrenalin acts to increase glucose availability during emergencies (Ellis, 1956; Foá, 1968). Their physiological roles may also differ in amphibians but with the exception of a single study (Hanke, 1974) the actions of the two hormones have not been compared simultaneously in the same species.

Supported by NIH Predoctoral Fellowship 5-flGM33-848-02.
One approach to the study of hormonal roles is to compare hormone actions during various phases of the life cycle when metabolic demands are different, such as at different times of the year or during different developmental stages. This research extends an initial seasonal comparison of adrenalin and glucagon activity in Rana pipiens (Farrar and Frye, 1977) and compares their effects in prometamorphic tadpoles and adults.

\section{MATERIALS AND METHODS}

\section{Animal Maintenance}

Male Rana pipiens weighing 30 to $80 \mathrm{~g}$ were obtained from the Nasco Supply Company of Oshkosh, Wisconsin. These animals were collected from the Red River Valley of North Dakota and shipped immediately except during the winter when they were stored outdoors prior to shipment.

Frogs were maintained in large tanks equipped with running tap water at $15-17^{\circ}$, with an air temperature of $19^{\circ}$, and with fluorescent lights on a 12-hr light:12-hr dark cycle. Frogs were fed crickets, force fed 1 to $2 \mathrm{~g}$ of beef liver twice a week, and fasted 3 to 5 days prior to each experiment. All animals were kept under these conditions for at least 2 weeks prior to use.

Tadpoles were reared from eggs and sperm of frogs from North Dakota. Ovulation and insemination were done by the method of Wright and Flathers (1961). Tadpoles were kept in enamel pans of dechlorinated water, were fed boiled and rinsed spinach, and were maintained at a water temperature of 20 to $22^{\circ}$ under a 
12-hr light:12-hr dark light regime. Animals were staged by the series of stages described by Taylor and Kolros (1946). Tadpoles of Stages XII-XV were utilized in all experiments.

\section{General Procedures}

Anesthesia. Anesthesia was necessary prior to blood sampling by heart puncture and tissue removal. Frogs were anesthetized by immersion in $0.5 \%$ tricaine methanesulfonate (Finquel, Ayerst Laboratories) for 10 to $15 \mathrm{~min}$. Tadpoles were immersed in $0.03 \%$ Finquel for 2 to $3 \mathrm{~min}$, or until a slight nudge failed to induce a swimming reflex.

Injection. Frogs were injected intraperitoneally in the lower abdomen. Tadpoles were injected intraperitoneally in the anterior abdominal wall via the operculum.

Adrenalin (Parke-Davis. $1 \mathrm{mg} / \mathrm{ml}$. as the hydrochloride) was injected after suitable dilutions with amphibian Ringers solution. Injection volumes were less than $0.10 \mathrm{ml}$ for adults and less than $0.01 \mathrm{ml}$ for tadpoles. Doses of $50 \mu \mathrm{g} / \mathrm{kg}$ to $1 \mathrm{mg} / \mathrm{kg}$ were used. All adrenalin solutions were kept on ice and were discarded after $6 \mathrm{hr}$; no discoloration indicative of oxidation was ever observed in these solutions.

Crystalline ox glucagon (Eli Lilly Co.) was dissolved in the accompanying diluent and diluted in amphibian Ringers. No injections exceeded $0.2 \mathrm{ml}$ for adults or $0.02 \mathrm{ml}$ for tadpoles. Doses of glucagon ranged from 50 $\mu \mathrm{g} / \mathrm{kg}$ to $2 \mathrm{mg} / \mathrm{kg}$.

Controls were given placebo injections of amphibian Ringers of $\mathrm{pH}$ equivalent to the hormone solutions.

Tisstre sampling. Blood samples of approximately 100 to $150 \mu \mathrm{l}$ were obtained by heart puncture. No anticoagulant was necessary for frog blood but tadpole blood was collected in glass capillaries containing sodium citrate crystals. Aliquots $(50 \mu \mathrm{l})$ of blood were then transferred to deproteinization solutions for glucose and lactate determinations.

liver and muscle samples for glycogen analysis were collected at the time of blood sampling. Midportions of the right gastrocnemius muscle and tips of three liver lobes were rapidly removed, blotted, weighed, and placed in hot $30 \% \mathrm{KOH}$. Entire tadpole livers were analyzed. Fifty to five hundred milligrams of tissue was digested per milliliter of $\mathbf{K O H}$.

\section{Chemical Procedures}

Blood carbohydrate analysis. Blood glucose was analyzed by the glucose oxidase technique (Glucostat. Worthington Biochemical Corp.). Blood lactate was analyzed enzymatically using the lactate dehydrogenase method of Scholz et al. (1959) provided in kit form by the Boehringer-Mannheim Corporation. The procedure was scaled down to fit the small blood sample volume.

Glycogen analysis. Liver and muscle samples were digested in hot $30 \% \mathrm{KOH}$ and glycogen precipitated with $95 \%$ ethanol according to the technique of Good et al. (1933). Precipitated and washed glycogen was dissolved and diluted to $50 \mathrm{ml}$ with distilled water. Aliquots containing 10 to $50 \mu \mathrm{g}$ of glycogen were analyzed for total reducing carbohydrate using the phenol-sulfuric acid method of Montgomery (1957).

\section{Liver Slice Techniques}

Livers were rapidly removed from spinal-sectioned frogs, placed in iced Ringers, and sliced free hand. Slices were blotted, weighed, and assigned to control or expcrimental flasks. Slices weighing 60 to $100 \mathrm{mg}$ were incubated in a water bath shaker in Erlenmeyer flasks containing $2 \mathrm{ml}$ of amphibian Ringers buffered with $0.1 M$ sodium bicarbonate. Preliminary experiments demonstrated that the hormones were most effective at $\mathrm{pH} 7.8$ and $25^{\circ}$ and these conditions were adhered to throughout. Hormones were added to the medium in $0.05 \mathrm{ml}$ of solvent just prior to adding the liver slice. After an incubation period of $30 \mathrm{~min}$ to $1 \mathrm{hr}$ the slices were removed. $50 \mu \mathrm{l}$ of the supernatant was deproteinized, and glucose content was analyzed as described for blood glucose. Usually 10 flasks, 2 controls and 2 flasks each of 4 hormone doses, could be obtained from each frog: 6 frogs were used per experiment. Tadpole liver slices were incubated as just described. About 10 to 12 Stage XII-XV tadpole livers were required for each 10 flasks. The tadpoles were immobilized by transection of the spinal cord or were precooled in ice water prior to the transection. Then livers were removed and placed in iced Ringers. Slices from 10 livers were mixed, blotted and weighed, and assigned to flasks. Each flask received 20 to $80 \mathrm{mg}$ of tissue.

\section{Statistics}

The Mann-Whitney $U$ test (Siegel, 1956) was used in comparing groups with sample sizes of less than 20. Means of groups larger than 20 and all groups from liver slice experiments were compared to using Student's $t$ test. In tests of significance a probability of $5 \%$ or less was considered to be significant.

\section{RESULTS}

\section{Effects of Adrenalin and Glucagon on Carbohydrate Metabolism of Intact Frogs and Tadpoles}

Frog blood glucose. Adrenalin (0.1 to 1.0 $\mathrm{mg} / \mathrm{kg}$ ) caused 172 to $200 \%$ increases in blood glucose by $3 \mathrm{hr}$ in summer and winter frogs (Fig. 1). A dose of $0.05 \mathrm{mg} / \mathrm{kg}$ was ineffective. The $1 \mathrm{mg} / \mathrm{kg}$ dose was considered to be pharmacologic since it caused extreme skin reddening and glandular secretion. Hyperglycemia was present by $1 \mathrm{hr}$ 


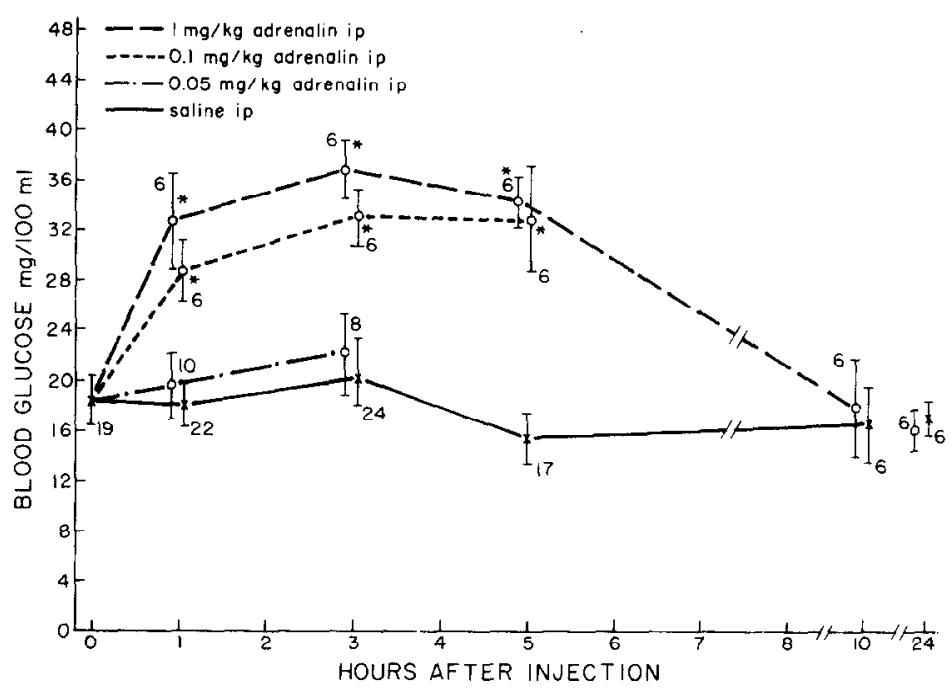

Fig. 1. Effects of different doses of adrenalin on frog blood glucose. Data of summer and winter experiments combined (means $\pm \mathrm{SE}$, numbers are numbers of animals in each group, asterisks indicate significant difference from controls, $P \leqslant 0.05$ ).

and lasted for at least $5 \mathrm{hr}$. By $10 \mathrm{hr}$ blood glucose had returned to normal.

The same dose $(1 \mathrm{mg} / \mathrm{kg})$ of glucagon was consistently less effective in producing hyperglycemia in winter than during summer and fall (Fig. 2). During the winter glucagon hyperglycemia was delayed in time of appearance and at $3 \mathrm{hr}$ was only
$170 \%$ above normal as compared with $200 \%$ during summer and fall. The level of hyperglycemia observed after injection of 1 $\mathrm{mg} / \mathrm{kg}$ glucagon in winter was similar to that seen after a $0.1 \mathrm{mg} / \mathrm{kg}$ dose in summer (Fig. 3). A $2.0 \mathrm{mg} / \mathrm{kg}$ glucagon dose in winter was comparable in its effect to a dose half that large in summer or fall (Fig. 3). A dose of

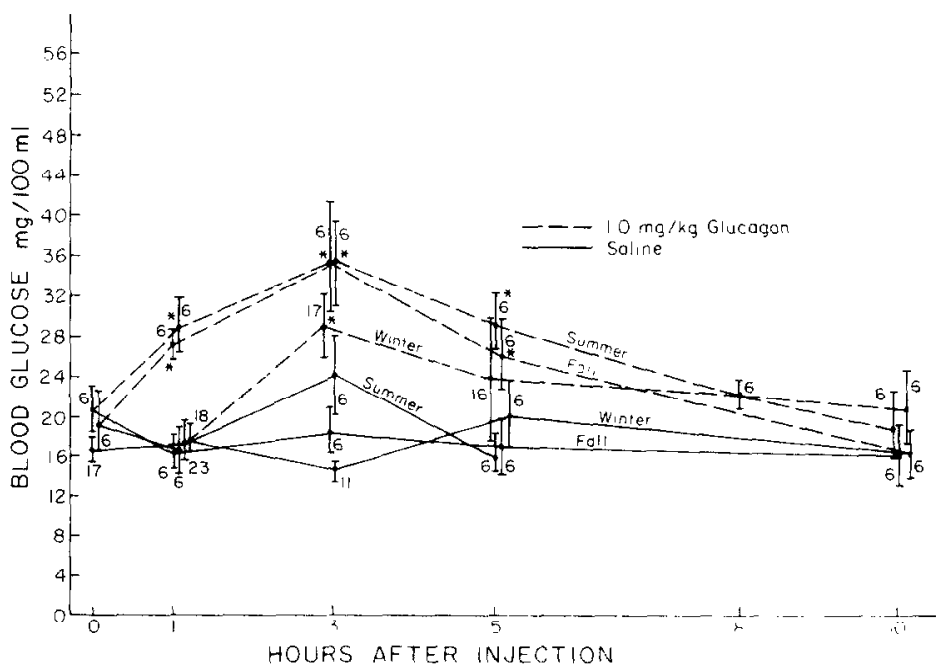

FlG. 2. Effects of glucagon on frog blood glucose in summer, fall, and winter (means $\pm S E$, numbers are numbers of animals in each group. asterisks indicate significant difference from respective seasonal control, $P \leqslant 0.05$ ). 


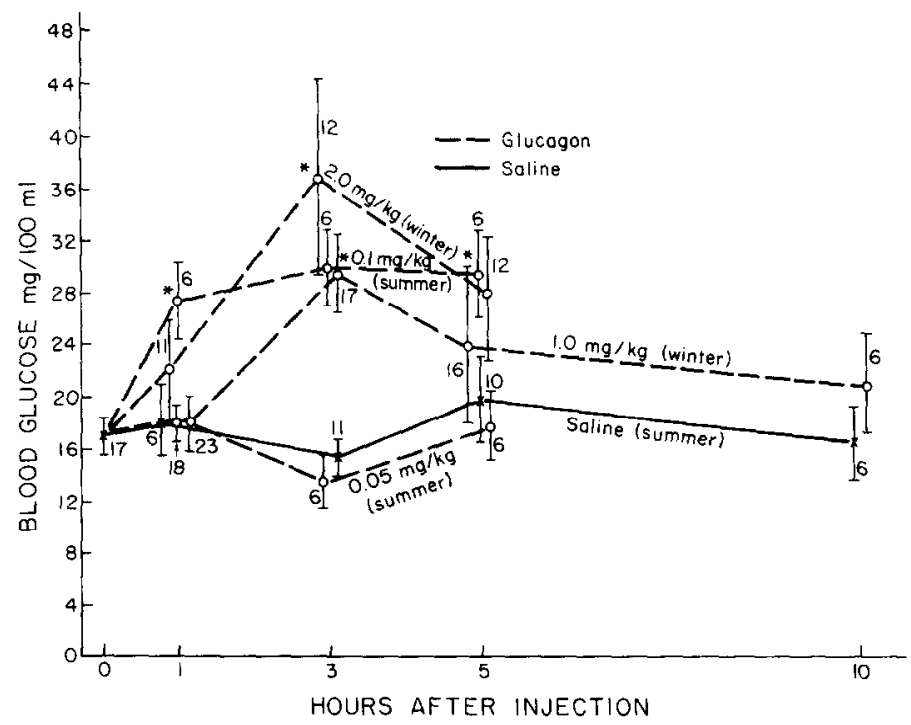

Fig. 3. Effects of different doses of glucagon on frog blood glucose (means $\pm \mathrm{SE}$, numbers are numbers of animals in each group, asterisks indicate significant difference from control, $P \leqslant 0.05$ ).

$0.05 \mathrm{mg} / \mathrm{kg}$ was ineffective in summer (Fig. 3). All glucose levels were normal by $10 \mathrm{hr}$ postinjection. The effects of adrenalin and glucagon were most similar during summer.

Frog blood lactate. Blood lactate responses to adrenalin and glucagon were analyzed in frogs collected in summer. A graded response to different adrenalin doses was observed (Fig. 4). Adrenalin at a dose of $1 \mathrm{mg} / \mathrm{kg}$ produced peak lactate concentrations at 1 and $3 \mathrm{hr}$ after injection, but lactate levels had dropped to control levels by $5 \mathrm{hr}$. Lower doses resulted both in lower peak responses and shorter durations of response. A dose of $0.05 \mathrm{mg} / \mathrm{kg}$ of adrenalin did stimulate an increase in lactic acid but was ineffective in elevating blood glucose (Figs. 1 and 4). The maximum mean level of lactate reached in the dose-response studies after adrenalin treatment was 33.4 $\mathrm{mg} \%$, which represents an increase of approximately $154 \%$ over the initial value of $13 \mathrm{mg} \%$. This percentage increase was slightly greater in magnitude than that observed for blood glucose $(100 \%$ increase, Fig. 1), but the response was not as prolonged. A dose of $0.1 \mathrm{mg} / \mathrm{kg}$ glucagon had no effect on blood lactate (Fig. 4). The ap- parent decrease at $1 \mathrm{hr}$ was of borderline statistical significance $(P=0.052)$.

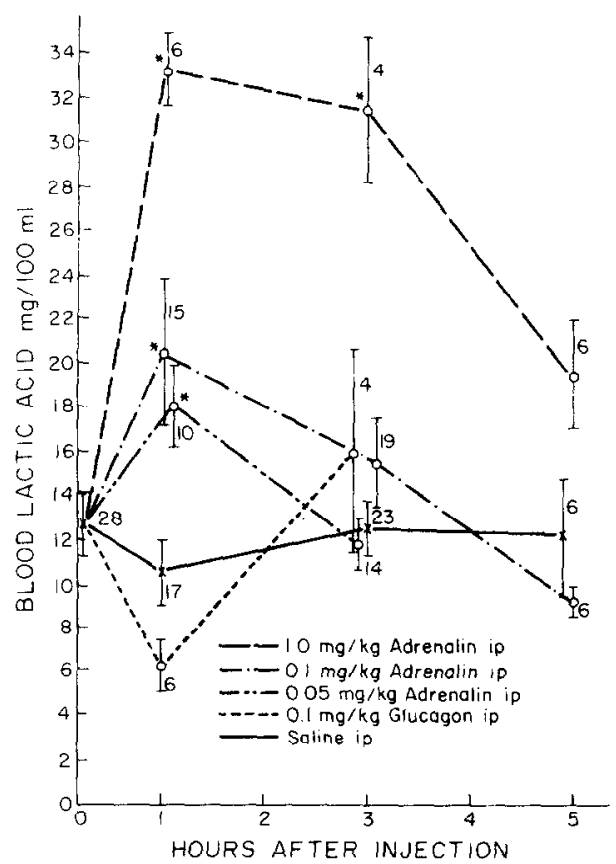

FIG. 4. Effects of different doses of adrenalin and glucagon on frog blood lactate (means $\pm S E$, numbers are numbers of animals in each group, asterisks indicate significant difference from control, $P \leqslant 0.05$ ). 
Frog muscle and liver glycogen. No changes in muscle and liver glycogen of summer frogs were seen in response to 1 $\mathrm{mg} / \mathrm{kg}$ of adrenalin or glucagon within $5 \mathrm{hr}$ after injection of the hormones. Mean muscle glycogen levels at the various intervals measured ranged from 0.8 to $1.2 \%$. Mean liver glycogen concentrations at the same intervals ranged from 5.9 to $9.4 \%$.

Tadpole blood glucose. Blood glucose was elevated by as much as $260 \%$ after adrenalin and $200 \%$ after glucagon at a dose of $1 \mathrm{mg} / \mathrm{kg}$ (Fig. 5). In both cases the response was apparent by 1 to $3 \mathrm{hr}$ but persisted for less than $5 \mathrm{hr}$. A statistically significant increase in blood glucose was not observed after a $0.1 \mathrm{mg} / \mathrm{kg}$ dose of adrenalin.

Tadpole blood lactate. Control lactate levels were variable presumably because of
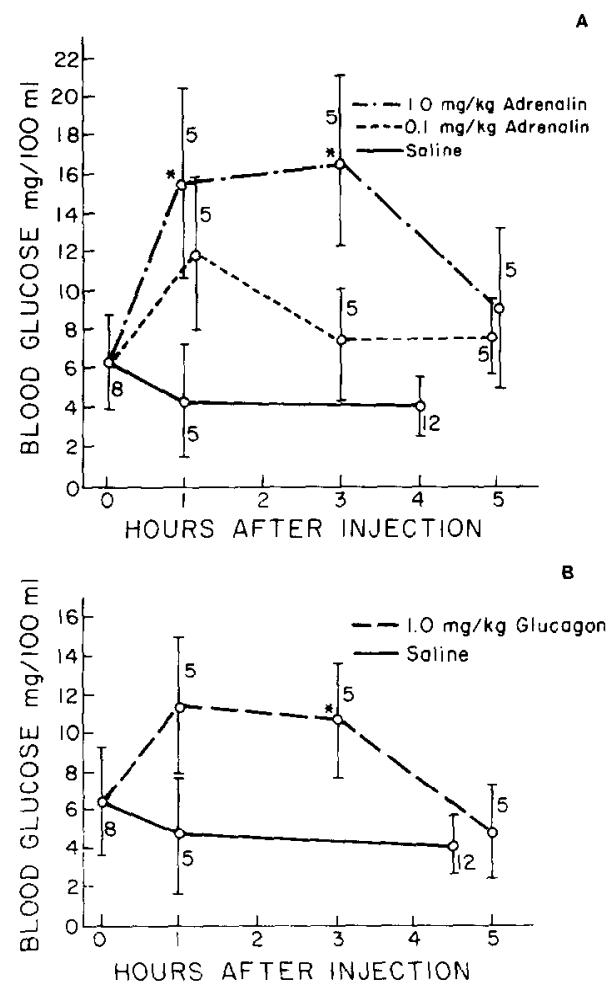

Fic. 5. (A) Effect of adrenalin on tadpole blood glucose. (B) Effect of glucagon on tadpole blood glucose. (Mean \pm SE. numbers are numbers of tadpoles in each group, asterisks indicate significant difference from controls, $P \leqslant 0.05$.) varying amounts of swimming activity. This was especially apparent at $1 \mathrm{hr}$ postinjection when any possible adrenalin effect was masked by lactacidemia in the controls (Fig. 6). At $5 \mathrm{hr}$ only the adrenalin-treated tadpoles had elevated lactate levels.

Tadpole liver glycogen. Liver glycogen depletion was observed in tadpoles receiving glucagon $(1 \mathrm{mg} / \mathrm{kg})$ but not adrenalin (Fig. 7). Glycogen levels were lower at $3 \mathrm{hr}$ $(1.5 \%)$ and $5 \mathrm{hr}(2.7 \%)$ than either the saline control tadpoles or the initial controls $(5.3 \%)$. Glycogen levels were variable and the reduced glycogen in controls at $1 \mathrm{hr}$ may have been due to increased activity. It is not known whether these animals were hyperglycemic since blood glucose experiments were performed on another group of tadpoles.

\section{Effects of Adrenalin and Glucagon on Glucose Release from Liver Slices}

In the absence of hormones frog liver slices released glucose at a rate of $1.6 \mu \mathrm{g} /$ $\mathrm{mg} / \mathrm{hr}$ (Table 1). Adrenalin stimulated glucose release at concentrations between 1.4 $\times 10^{-6}$ and $1.4 \times 10^{-4} M$; those concentrations below and above these levels were ineffective. Glucagon stimulated glucose re-

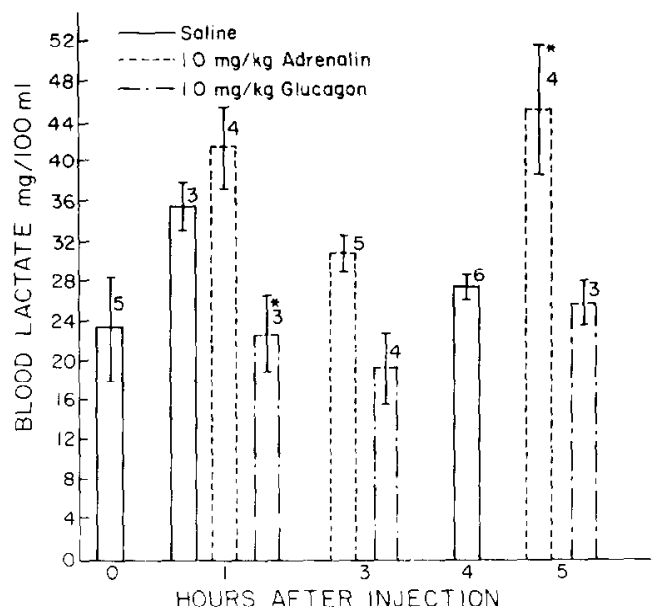

FIG. 6. Effect of adrenalin and glucagon on tadpole blood lactate (means \pm SE, numbers are numbers of animals in each group, asterisks indicate significant difference from controls, $P \leqslant 0.05$ ). 


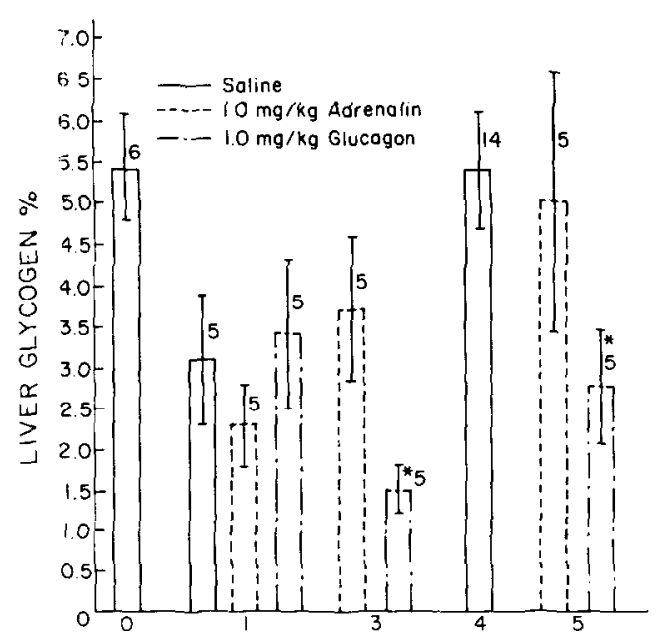

HOURS AFTER INJECTION

FIG. 7. Effect of adrenalin and glucagon on tadpole liver glycogen (means \pm SE, numbers are numbers of animals in each group, asterisks indicate significant difference from controls, $P \leqslant 0.05$ ).

lease at concentrations as low as $7.2 \times 10^{-7}$ $M$. Glucose release rates increased with increasing hormone concentrations up to and including $7.2 \times 10^{-5} \mathrm{M}$. Adrenalin increased the rate of glucose release from 1.6 to $3 \mu \mathrm{g} / \mathrm{mg} / \mathrm{hr}$, an $88 \%$ rise above initial levels. The highest dose of glucagon caused an increase of $175 \%$ from 1.6 to $4.4 \mu \mathrm{g} /$ $\mathrm{mg} / \mathrm{hr}$.

Liver slices from tadpoles that had been spinal sectioned and had their livers removed at room temperature were not responsive to hormone treatment (Tables IA and $B$ ). However, the rate of glucose release in control slices was high $(2.6 \mu \mathrm{g} /$ $\mathrm{mg} / \mathrm{hr}$ ) compared to the rate of release from control frog slices. When the tadpoles were cooled prior to spinal section and liver removal, a significant effect of adrenalin was seen at all concentrations from $1.4 \times 10^{-6}$ to $1.4 \times 10^{-4} M$ (Table $1 \Lambda$ ). Glucagon caused significant increases in glucose release from liver slices of cooled tadpoles at concentrations between $7.2 \times 10^{-5}$ and $7.2 \times 10^{-8} \mathrm{M}$ though the response at this lower concentration was of borderline significance $(P=$ 0.05 ) in one experiment and not significant in the other (Table 1B). Large release rates
(11.4 $\mu \mathrm{g} / \mathrm{mg} / \mathrm{hr}$ ) were found at the highest glucagon dose.

Adrenalin and glucagon responses were dissimilar at higher dose levels in both the frog and tadpole liver slices. Adrenalin was increasingly less effective above the $1.4 \times$ $10^{-6} M$ level in frogs and the $1.4 \times 10^{-4} M$ level in tadpoles. As the adrenalin dose was increased the amount of blood appearing in the medium also increased. A plausible explanation for these observations may be that the hormone caused enough constriction of blood vessels to effectively hinder its own penetration of the inner tissue mass, while causing blood to be extruded from the vessels. In contrast glucagon showed continually increasing effects at high doses.

All the properties of adrenalin and glucagon dose-response relationships observed in frog liver slices were also seen in tadpole liver slices. This included even the peculiar responses at high doses. Two possible differences were observed: Tadpole slices were slightly more sensitive to glucagon than were frog slices, and tadpole slices had a greater potential for increasing glucose output in response to large glucagon doses.

\section{DISCUSSION}

Adrenalin and Glucagon Effects in Adults

Two lines of evidence suggest that adrenalin and glucagon differ in their roles as hormones regulating carbohydrate metabolism in amphibians. First, adrenalin but not glucagon causes lactic acid accumulation in the blood, presumably by stimulating muscle glycogenolysis. Second, patterns of response differ when the two hormones are given to frogs collected during different seasons of the year.

Adrenalin, in mammals, acts primarily on skeletal muscle causing glycogenolysis to lactate while glucagon is more effective in stimulating liver glycogenolysis to glucose (Sokal and Sarcione, 1958). Adrenalin (Bufo bufo, Hermansen and Jørgensen, 1969; Triturus vulgarus, Matei-Vladescu, 1965; Xenopus laevis, Wong and Hanke, 1977; Rana catesbeiana. Herman, 1977; 


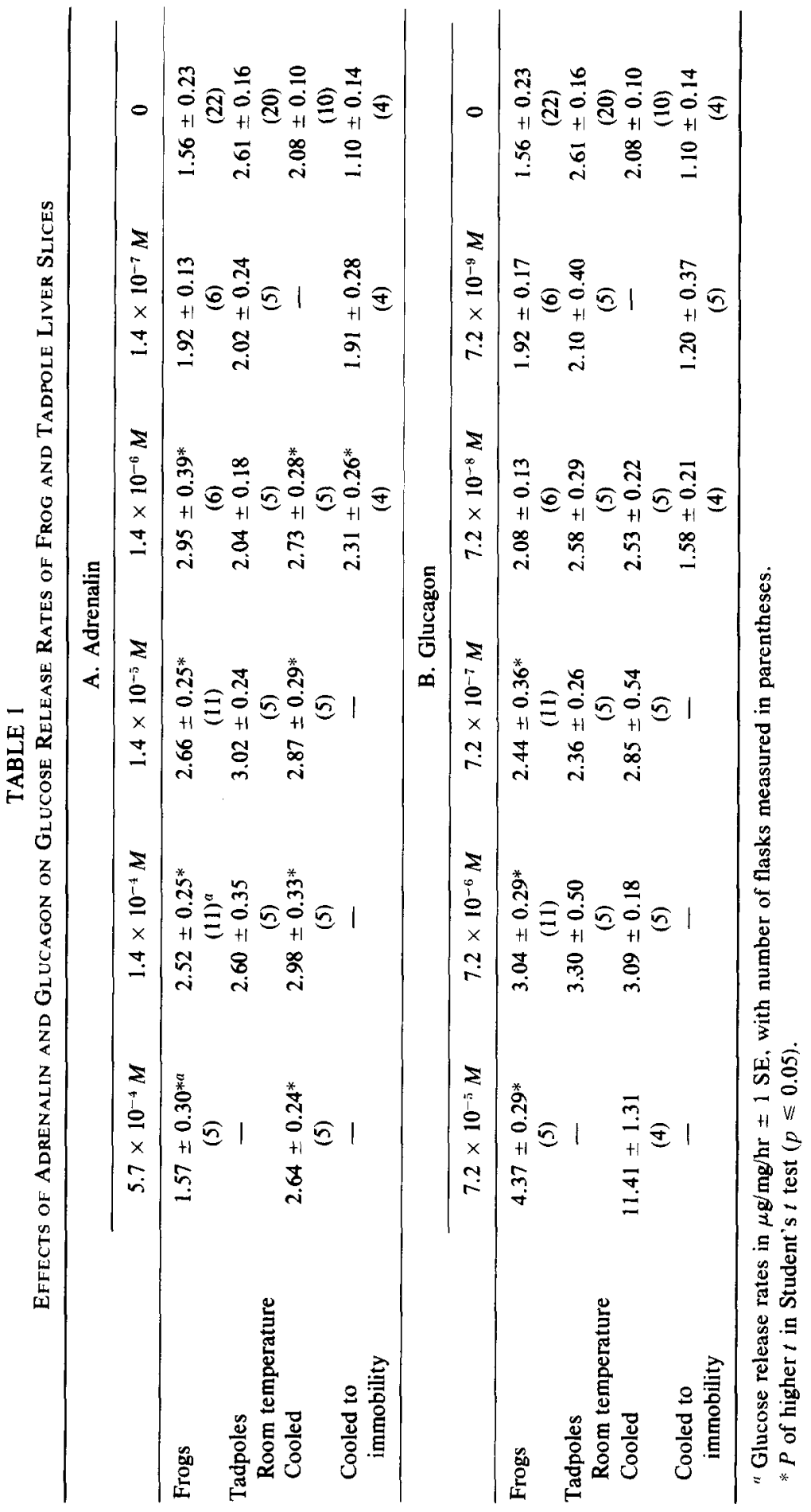


Rana temporaria, Hanke, 1974) and glucagon (Rana temporaria, Hanke and Neumann, 1972; Rana catesbeiana, Wright, 1959; Penhos and Ramey, 1973; Bufo arenarum, Penhos and Lavintman, 1964; Bufo marinus, Penhos and Ramey, 1973) cause hyperglycemia in a wide variety of species including Rana pipiens. That each hormone potentially stimulates liver glycogenolysis is supported by the increased release of glucose by liver slices following incubation with adrenalin and glucagon. This has been demonstrated by our work as well as by those of Tindal (1956), Hanke (1974), and Brown et al., (1975) who studied Amphiuma liver fragments in culture. Lack of glycogen depletion following adrenalin and glucagon treatment is not necessarily inconsistent with their action in stimulating gly. cogenolysis but can be explained by problems with detecting very small changes in glycogen when large amounts are present. Hanke and Neumann (1972) reported that glucagon caused liver glycogen depletion in Rana temporaria only in the summer when glycogen concentrations were low. Glucagon does not cause blood lactate accumulation in Rana pipiens while adrenalin is potent in this regard. This suggests that in amphibians, as in mammals, adrenalin is more important in the regulation of glycogenolysis in muscle than in liver.

The best evidence for differing physiological roles comes from seasonal studies where distinct seasonal differences in responses to those hormones can be described. Adrenalin effects on blood glucose and lactate in the fall are double that observed in either summer or winter (Farrar and Frye, 1977). Glucagon effects remain unchanged in fall but its effects are somewhat reduced in winter as compared to either summer or fall. As seen in the present study, twice as much glucagon was required in winter to duplicate its potency in summer or fall.

The specific physiologic roles of these hormones at different times of the year is speculative. Adrenalin may be important in the preparation for overwintering. Via such effects as increasing muscle glycogenolysis, increasing oxygen consumption (Watlington et al., 1965; Harri and Hedenstam, 1972), increasing the $Q_{10}$ effect of temperature on glucose release from liver (Tindal, 1956), adrenalin could increase the capacity of the frog to remain active as temperatures drop in the fall. These effects could facilitate migration in species such as Rana pipiens where summers are often spent at considerable distances from hibernation sites (Merrell, 1970). Adrenalin and thyroxine may be important mediators of metabolic changes occurring during temperature acclimation (Lagerspetz, 1977). If glucagon is more involved in acute glucose regulation then the reduction in sensitivity of winter frogs may reflect the generally diminished metabolic demands of overwintering animals. Perhaps the need for a glycogenolytic hormone acting primarily on the liver is minimal during this period while adrenalin may still be necessary because of its suspected contribution to cold survival.

\section{Adrenalin and Glucagon Effects in Tadpoles}

Preliminary studies indicate that Rana pipiens tadpoles (Taylor and Kollros, 1946, Stages XII-XV) respond to both adrenalin and glucagon. These hormones could contribute significantly to several metamorphic events. Through their insulin antagonistic activities they could promote the initiation of pancreatic $\beta$-cell function in a manner suggested by Frye $(1964,1965)$, the subsequent insulin secretion in response to glucose, and the achievement of adult regulatory patterns. Equally important may be the functions of these hormones in mobilizing glucose during metamorphic climax when the tadpoles cease feeding, rapidly mobilize liver glycogen stores (Farrar and Frye, 1973), and presumably utilize the released glucose until feeding can be resumed. 


\section{REFERENCES}

Brown, D., Fleming, N, and Balls. M. (1975). Hormonal control of glucose production by $\mathrm{Am}$ phiuma means liver in organ culture. Gen Comp. Endocrinol. 27, 380-388.

Copeland, D. L., and deRoos, R. (1971). Effect of mammalian insulin on plasma glucose in the mud puppy (Necturus maculosus). J. Exp. Zool. 178, $35-44$

Ellis, S. (1956). Metabolic effects of epinephrine and related amines. Pharmacol. Rev. 8, 485-562.

Farrar, E., and Frye, B. E. (1973). Comparison of blood glucose and liver glycogen of larval and adult frogs (Rana pipiens). Gen. Comp. Endocrinol. 21, 513-516.

Farrar, E., and Frye, B. E. (1977). Seasonal variation in the effects of adrenalin and glucagon in Rana pipiens. Gen. Comp. Endocrinol. 33, 76-81.

Foá. P. P. (1968). Glucagon. Ergeb. Physiol. Biol Chem. Exp. Pharmakol. 60, 141-219.

Frye, B. E. (1964). Metamorphic changes in the blood sugar and the pancreatic islets of the frog, Rana clamitans. J. Exp. Zool. 155, 215-223.

Frye, B. E. (1965). Hypertrophy of the islets of Langerhans of frog tadpoles after partial pancreatectomy. J. Exp. Zool. 158, 133-139.

Good, C. A., Kramer, H., and Somogyi, M. (1933). The determination of glycogen. $J$. Biol. Chem. 100, 485-491.

Hanke, W. (1974). Die hormonale Regulation des Stoffwechsels bei Amphibien. Fortschr. Zool. 22. $431-455$.

Hanke, W., and Neumann, V. (1972). Carbohydrate metabolism in amphibia. Gen. Comp. Endocrinol. Suppl. 3, 198-208.

Harri, M., and Hedenstam, R. (1972). Calorigenic effect of adrenaline and noradrenaline in the frog, Rana temporaria. Comp. Biochem. Physiol. A 41, $409-419$.

Herman, C. A. (1977). Comparative effects of epinephrine and norepinephrine on plasma glucose and hematocrit levels in the American bullfrog (Rana catesbeiana). Gen. Comp. Endocrinol. 32 , $321-329$.

Hermansen, B., and Jørgensen, C. B. (1969). Blood glucose in male toads (Bufo bufo): Annual variation and hormonal regulation. Gen. Comp. Endocrinol. 12, 313-321.

Lagerspetz, K. Y. H. (1977). Interactions of season and temperature acclimation in the control of metabolism in Amphibia. J. Therm. Biol. 2, $223-231$.

Leibson, L. G., and Plisetskaya, E. M. (1973). Fffects of hormones in poikilothermic vertebrates. Int . Encycl. Pharm. Ther. 85, 625-684.

Matei-Vladescu, C. (1965). Research on the carbohydrate metabolism regulation in amphibians. The action of insulin and adrenalin in Triturus valgaris. Rev. Roum. Biol-Zool. 10, 166-169.

Merrell, D. J. (1970). Migration and gene dispersal in Rana pipiens. Amer. Zool. 10, 47-52.

Montgomery, R. (1957). Determination of glycogen. Arch. Biochem. Biophys. 67, 378-383.

Penhos, J. C., and Lavintman, N. (1964). Total pancreatectomy in toads: effect of hypophysectomy and glucagon. Gen. Comp. Endocrinol. 4. $264-270$.

Penhos, J. C., and Ramey, E. (1973). Studies on the endocrine pancreas of amphibians and reptiles. Amer. Zool. 13, 667-698.

Scholz, R., Schmitz, H., Bücher, Th., and Lampen, J. O. (1959). Über die Wirkung von Nystatin auf Bäckerhefe. Biochem. Z. 331, 71-82.

Seiden, G. (1945). The response of the pancreatic islands of the frog (Rana pipiens) to alloxan. Anat. Rec. 91. 187-197.

Siegel, S. (1956). "Nonparametric Statistics for the Behavioral Sciences." McGraw-Hill, New York.

Sokal, J. W., and Sarcione, E. J. (1958). Failure of blood glucose levels to reflect hepatic glycogenolysis; experiences with glucagon. $J$. Exp. Biol. Med. 98, 879-881.

Taylor, A. C., and Kolros, J. J. (1946). Stages in the normal development of Rana pipiens larvae. Anat. Rec. 94, 7-23.

Tindal, J. S. (1956). Glycogenolysis in the liver of the common frog, Rana temporaria. J. Exp. Biol. 33. 196-210.

Umminger. B. L. (1977). Relation of whole blood sugar concentrations in vertebrates to standard metabolic rate. Comp. Biochem. Physiol. A 56, $457-460$.

Watlington. C: O., Burke, P. K., Campbell, A. D., and Huf, F. G. (1965). Systemic effects of epinephrine in the frog. J. Cell Comp. Physiol. 65, $337-354$.

Wong, K. L., and Hanke, W. (1977). The effects of biogenic amines on carbohydrate metabolism in Xenopus laevis Daudin. Gen. Comp. Endocrinol. 31, 80-90.

Wright, P. A. (1959). Blood sugar studies in the bullfrog. Rana catesbeiana. Endocrinology 64 . $551-558$.

Wright, P. A., and Flathers, A. R. (1961). Facilitation of pituitary induced ovulation by progesterone in early fall. Proc. Soc. Exp. Biol. Med. 106. $346-347$. 